\title{
Driving Fatigue and Performance among Occupational Drivers in Simulated Prolonged Driving
}

\author{
SzeSeen Kee \\ Department of Community Health, Faculty of Medicine and Health Science \\ University Putra Malaysia, 43400 Serdang, Selangor Darul Ehsan, Malaysia \\ Tel: 63-8947-2395 E-mail: sinngerkee@yahoo.com \\ Shamsul Bahri Mohd Tamrin \\ Department of Community Health, Faculty of Medicine and Health Science \\ University Putra Malaysia, 43400 Serdang, Selangor Darul Ehsan, Malaysia \\ Tel: 60-3-894-2395 E-mail: uvea_2000@yahoo.com \\ YongMeng Goh \\ Department of Veterinary Preclinical Science, Faculty of Veterinary Medicine, \\ University Putra Malaysia, 43400 Serdang, Selangor Darul Ehsan, Malaysia \\ Tel: 60-3-8946-8338 E-mail: gohyongmeng@gmail.com
}

The research is financed by University Putra Malaysia (Research University Grant Scheme) Vote No. 91236

\begin{abstract}
Introduction: Motor vehicle accident is a major problem in Malaysia. The statistics shows an increasing number of accidents (year 1997 to 2007). Fatigue and drowsiness among the drivers has been identified as one of the main reasons behind fatal crashes and injuries especially driving in long and monotonous motorway. This study aims to determine the driver's driving performance and physiological change of EEG in association with external factors such as driving condition and environmental background factors in a prolonged simulation study. Result: The study showed that time-on-task effect had significantly deteriorated drivers' alertness and impaired driving performance in an extended driving period, when certain driving condition and environmental factors considered. Conclusion: This study shows that prolong driving had significantly induced drivers' fatigue level exclusively with monotonous environment. Extended driving period deteriorated drivers' performance, revealing that time-on-task effect could possibly put drivers on a higher risk to be involved in traffic accident.
\end{abstract}

Keywords: Fatigue, Drowsiness, Driving performance, EEG, Simulation

\section{Introduction}

Motor vehicle accident, also known as road traffic accident which involves cars, motorcycles and public transport is a major problem in Malaysia. According to the Malaysian Institute of Road Safety (MIROS), the rate of road accidents in Malaysia is one of the highest compared to other countries in the world. A ten-year road traffic statistic showed that the total number of accidents had risen from 215,632 cases (1997) to 363,314 cases in 2007. This is equivalent to 3.73 deaths for every 10000 registered vehicles in the same year. Recently, occupational vehicle accidents had recorded an alarming increase in serious injury and death. Among the most significant is the fatality involving bus crash that had increased by 58 percent from year 2006 to 2007 . These incidents happened mostly due to human errors on the drivers' part (e.g. speeding, losing control over the vehicle, overtaking, fatigue and drowsiness), environmental condition as well as the vehicle conditions ( $\mathrm{Ng}$ and Selva, 2003).

Driving fatigue, which is described as a feeling of drowsiness due to extended driving period, monotonous road condition, adverse climatologically environment or drivers' individual characteristics are direct or contributing factor to road accidents. Subjective feeling of fatigue which combined with negative effects on performance due to time spent on cognitively demanding tasks (Meletis and Barker, 2004) can somehow affect the driving 
performance due to sleepiness, monotonous driving environment condition and the length of driving period as previous studies proved (Otmani et al., 2005; Papadelis et al., 2007; Zaharah and Law, 2004). A study pointed out that 37.7 percent of commercial bus drivers in Malaysia had encountered fatigue during driving (Muhammad et al., 2008) where the long driving duration and awkward working hours had synergistic effect in inducing the onset of fatigue (Norlen et al., 2008).

Some risk factors have been identified as playing important roles in the occurrence of fatigued-traffic accidents. For instance, Dobbie (2002) determined that prolonged driving without rest can increase the fatigue level and deteriorate the driving performance. Long duration of driving, inadequate sleep and other cumulative factors caused the sleep deprived drivers to make higher number of right edge- line crossings and other errors (Otmani et al., 2005; Philip et al., 2003). Apart from fatigue factors, studies have also shown that working duration and sleep deprivation, as a result of disruption of an individual's routine sleep cycle (Philip et al., 2003; Philip, 2005; Tippayanate, 2006), clearly contributed to the deterioration of driving performance. Reaction time was reported to have slowed by 18 percent while stopping distance increased by 7.6 percent in a sleep deprived individuals (Tippayanate, 2006). Driving behavior and performance is also shaped in part by road environments (Muhammad et al., 2008; Norlen et al., 2008). Therefore, it is crucial to understand factors or determinants that will affect a driver's driving behavior, cognitive and driving performance.

Previous studies done had limited information on driving fatigue and focused only on commercial bus drivers through questionnaire and salivary cortisol (Muhammad et al., 2008; Norlen et al., 2008). Driving fatigue assessment under real-life driving condition for prolonged driving period and monotonous driving environment has not been reported yet. In addition, very little was known about driver's physiological change of electroencephalogram (EEG) during the onset of fatigue which may affect the driving performance in further. Therefore, this study aims at determining the effects of prolonged driving and the resultant driving fatigue on driving performance (as measured by RORIs and LSVs) and their correlations with EEG changes. Driving simulation was also simulated for daytime and night-time driving to determine the role of driving environment in inducing the changes observed.

\section{Materials and methods}

\subsection{Subjects}

Twenty-five occupational drivers, aged between 23 to 53 who had driving experience for at least 2 years, were recruited in this experiment. They were male drivers assigned into two groups [group $\mathrm{A}=13$, drove in daytime; group $\mathrm{B}=12$, drove in night-time condition]. All drivers were healthy (evaluated through questionnaire) and free from simulator sickness. They used to drive regularly day or night time during their working days. Drivers were trained for 15-min on the driving simulator before the trial. Written consent was obtained after they had agreed to volunteer for the trial. General experimental procedures were briefed to the subjects during a short familiarization and learning period on the simulator.

\subsection{Apparatus}

A custom made driving simulator system with modified vehicle instruments and controls was shown in Figure 1. A video screen was made as the "in-car" view and projected with a 32 inch LCD screen television located about 1 meter from the driver. The display unit reproduced town area, trunk road and motorway scenery with computer- generated pictures simulating daytime and night time driving condition. A total of 5 laps driving journey (each lap $=50 \mathrm{~km}$ ) was simulated with different sceneries. All the simulated roadways were in two lanes. Drivers were allowed to overtake the in front vehicles. The modified traffic velocity along the driving task was light. The speed limit legalized in town area, trunk road and motorway was $50 \mathrm{~km} / \mathrm{h}, 60 \mathrm{~km} / \mathrm{h}$ and $90 \mathrm{~km} / \mathrm{h}$ respectively.

\subsection{Experimental procedure}

Drivers were requested to complete a total of $250 \mathrm{~km}$ driving journey by abiding to all driving rules in force within a given time limit. They were instructed to cover the journey within 3 hours. All the drivers were told to refrain from smoking, drinking coffee, tea or alcohol and taking medicine 24 hours before the test. They were asked to have a habitual amount of sleep the night before the experiment to avoid sleep deprivation.

\subsection{Data collection}

\subsubsection{Driving measures}

The method of calculating driving errors was described by (Campagne et al., 2004). Running-of-the roads (RORI) index was measured for each second by the amplitude of the exit. It consisted of crossing over to the emergency lane (EL) or the continuous white line on the left-hand hedge of the passing lane. When the vehicle stays in the 
traffic lanes, the score was 0. Otherwise, it equals the distance between left front wheel and the EL for a RORI on the left-hand side and the distance between the right edge line for a RORI in the central reservation (CR) (Figure 2). The penalty is calculated for $1 \mathrm{~min}$ and corresponds to the square root of the sum of the RORI amplitudes squared for each second.

Running-off-the-road index: Penalty / min

$$
=\sqrt{\left(\sum \text { amplitude }^{2}\right)}
$$

For Large Speed Variation (LSV), a subject was penalized if an absolute difference between the vehicle speed and the highest speed authorized in the segment of road considered is calculated for each second. If the absolute difference is more than $20 \mathrm{~km} / \mathrm{h}$, the subject will get a penalty (per second) proportional to the number of kilometers per hour above the speed authorized. The sum of penalty is made for each minute on the whole experiment.

If $\Delta$ speed $>20$, then penalty (per second)

$$
=(\Delta \text { speed } / 10)-1
$$

\subsubsection{Electroencephalographic (EEG) measures}

During each driving session, the subjects EEG signals were recorded using an ML870 Powerlab 8/30 (ADInstruments, Australia). The elastic electrocap was used to record EEG signals from positions F3, F4, C3, C4, $\mathrm{O} 1$ and $\mathrm{O} 2$ as per the 10-20 electrode arrangement system. Contact impedance between electrode and cortex remained below $5 \mathrm{k} \Omega$ throughout the entire experiment. The EEG data was recorded with 16 bit quantitation at $1024 \mathrm{~Hz}$ sampling rate. Fast Fourier Transform was performed and spectral power of the EEG waves was determined for theta $(\theta)(4-8 \mathrm{~Hz})$, alpha $(\alpha)(8-12 \mathrm{~Hz})$ and beta $(\beta)(12-25 \mathrm{~Hz})$. A relative band ratio of $(\alpha \theta) / \beta$ was calculated to assess fatigue levels. In addition, 10-min epochs were used as per techiqued described by (Otmani et al., 2005).

\subsection{Statistical analysis}

Datasets were analyzed using SPSS software. Before commence the data analysis, all the EEG spectral powers were transformed into $\log _{10}$ to conform its normality. Driving performance index (RORI and LSV) and EEG spectral powers were compared across time at intervals of 10 minutes (10-min epoch) to determine possible changes when fatigue sets in. The different types of road condition were included to look at its influence toward drivers' driving performance and their physiological change of EEG spectral powers. This was done using the one-way repeated measure analysis of variance procedure (repeated measure ANOVA). Split plot ANOVA test was used to evaluate how driving conditions affected both driving performance and EEG spectral powers with time and also road conditions. Lastly, two-way ANOVA test was used to determine the effect of rain event towards drivers' driving performance and EEG spectral powers between daytime and night-time driving condition.

\section{Results}

\subsection{Analysis of physiological data (EEG spectral power)}

Mauchly's test indicated that the assumption of sphericity had been violated $(p<.05)$, therefore degree of freedom were corrected using Huynh-Feldt estimates of sphericity.

The time-on-task separated into ten 10-min epoch had significantly increased the EEG spectral powers in alpha, beta and theta bands $[F(3.34,53.38)=3.01, \mathrm{p}<.05 ; F(4.40,65.96)=7.43, \mathrm{p}<.01 ; F(4.22,67.46)=2.85, \mathrm{p}<.05$, respectively]. The post hoc test for alpha band revealed a significant difference in driving time affecting EEG spectral power of alpha, particularly after driving for 50 to 60 minutes period, regardless of driving in day or night-time condition $[\mathrm{F}(3.60,53.96)=0.29, \mathrm{p}>.05]$ (Figure 3a). Also, a significant difference in driving time affecting beta band was seen between 30 to 40 minutes and 60 to 70 minutes period, regardless driving in day or night-time condition $[\mathrm{F}(4.77,66.78)=0.31, \mathrm{p}>.05]$ (Figure 3b). Similarly, EEG spectral power of theta band had shown a significant difference in driving time during the first 10 to 20 minutes period. However, prolonged driving in day or night-time condition had negligible effects on theta band $[F(4.57,68.52)=0.37, p>.05]$ (Figure $3 \mathrm{c})$.

It was found that EEG spectral power in alpha, beta and theta bands had significant different with types of road conditions $[F(2.74,65.78)=4.803, \mathrm{p}<.01 ; F(3.15,75.56)=10.866, \mathrm{p}<.01 ; F(3.56,85.40)=5.352, \mathrm{p}<.01$, respectively], except (alpha theta)/beta ratio $[F(3.49,69.89)=1.881, \mathrm{p}>.05]$ (Table 1$)$. The post hoc test revealed 
that there is a significant different of alpha band found between town area with trunk road $[F(1,24)=5.65$, $\mathrm{p}<.05]$, trunk road with highway (after toll) $[F(1,24)=6.03, \mathrm{p}<.05]$, and also road curve with highway $[F(1$, $24)=9.30, p<.01]$. Similarly, a significant different of beta band was found between trunk road with highway (after toll) $[F(1,24)=7.99, \mathrm{p}<.01]$, and road curve with highway $[F(1,24)=7.25, \mathrm{p}<.05]$. For the theta band, a significant different was found between town area with trunk road $[F(1,24)=10.05, \mathrm{p}<.01]$, and trunk road with highway (after toll) $[F(1,24)=4.31, \mathrm{p}<.05]$. However, no significant difference of all EEG spectral power of alpha, beta, theta and (alpha theta)/beta band ratio were found with six types of road conditions when considered the driving conditions, either driving in daytime or night-time ( $\mathrm{p}>.05)$.

When considered two driving conditions, the result showed no significant difference ( $p>.05)$ of all EEG indices between rain and no rain event (Table 3). Although the mean of EEG spectral powers in alpha, beta and theta bands were higher observed when no rain compared with the present of rain, however, the data were not significantly proved.

\subsection{Driving performance}

Mauchly's test indicated that the assumption of sphericity had been violated $(p<.05)$, therefore degree of freedom were corrected using Huynh-Feldt estimates of sphericity.

When considered the time-on-task effect, the driving performance index of RORI and LSV has significantly increased with driving duration $[F(3.46,55.29)=50.59, \mathrm{p}<.01 ; F(5.57,78.00)=37.51, \mathrm{p}<.01$, respectively $]$. The post hoc test for both driving performance index, RORI and LSV showed a significant difference in driving times affecting RORI and LSV, particularly the last 10 minutes period, RORI index was significantly higher than that for the first 10 minutes period $(\mathrm{p}<.0001)$ while the LSV index at 80 minutes was significantly higher than the first 10 minutes period $(\mathrm{p}<.001)$. The difference in mean RORI and LSV index between the first and ninth period, and first and eighth period was 46.07 and 196.32, accordingly. However, no significant difference of both RORI and LSV index found during the prolonged driving when considered daytime or night-time conditions $(\mathrm{p}>.05)$ (Figure $4 \mathrm{a}$ and $4 \mathrm{~b})$.

The driving performance index of RORI and LSV has significantly changes with different types of road conditions $[F(2.11,50.63)=180.31, \mathrm{p}<.01 ; F(2.57,61.78)=122.09, \mathrm{p}<.01]$ (Table 2). The post hoc test shows that a significant different of RORI was found between town area with trunk road $[F(1,24)=52.02, \mathrm{p}<.01]$, trunk road with highway (after toll) $[F(1,24)=15.09, \mathrm{p}<.01]$, highway (after toll) with uphill downhill $[F(1$, $24)=131.35, \mathrm{p}<.01]$, uphill downhill with road curve $[F(1,24)=28.03, \mathrm{p}<.01]$, and also road curve with highway $[F(1,24)=37.27, \mathrm{p}<.01]$. Similarly, LSV index has significantly change between town area with trunk $\operatorname{road}[F(1,24)=86.11, \mathrm{p}<.01]$, trunk road with highway (after toll) $[F(1,24)=127.96, \mathrm{p}<.01]$, highway (after toll) with uphill downhill $[F(1,24)=9.31, \mathrm{p}<.01]$, and also road curve with highway $[F(1,24)=20.23, \mathrm{p}<.01]$. However, both RORI and LSV index showed no significant difference with the varied types of road conditions when driving in day or night-time conditions ( $p>.05)$.

In determining the rain effect to driving performance index, the statistical analysis of data revealed that influence of rain event itself had contributed 50.2 percent to the RORI index, regardless driving in day or night-time condition $[F(1,42)=45.74, \mathrm{p}<.001]$. The mean of RORI (43.43) was higher observed when no rain present compared to 25.40 with the rain present. Meanwhile, the LSV index showed no significant difference when considered the rain effect itself $[F(1,46)=2.93, \mathrm{p}>.05]$ as well as in two driving conditions (Table 4).

\section{Discussion}

The use of driving simulator enabled us to simulate actual driving situation in a safe and controlled environment [Campagne et al., 2004; Liang et al., 2005; Otmani et al., 2005; Philip et al., 2003; Roge et al., 2004; Schier, 2000). The driving simulator allowed us to conduct the study of long and monotonous driving task with different kinds of road and climatologically event, which in real traffic scene, could possibly bring to severe accidents.

\subsection{The effect of time-on-task on drivers' physiological data and driving performance}

The results of drivers' physiological data of EEG clearly showed the decrement of drivers' alertness level can be seen by progressive increase in spectral power in alpha band. However, our findings are slightly different from previous studies found. Campagne et al. (2004) discovered that increase of spectral power in both alpha and theta band was significantly entailed a progressive deterioration of driver's vigilance level during an extended driving period. Otmani et al. (2005) agreed with this statement, showing that time on driving task alone, able to decrease driver's alertness level, particularly when the driver suffered sleep deprivation. In contrast, we observed that there was an increment of spectral power in beta band which indicated that drivers are still in awake stage when the driving duration is getting longer. The conflicts of the statement could be explained by drivers just started to 
feel tire but not in drowsy state yet in this prolonged driving task. A study from Schier (2000) stated that alpha rhythm rise up significantly in lap 5 compared with lap 2 showing that there was an overall reduction of drivers' attention with extended driving periods. Lal and Craig (2001) mentioned that theta rhythm is normally associated with drowsiness and sleep, and replaced the alpha band when onset of sleep. In our study, we believed that drivers have not yet been reaching the level of drowsy or fatigue, but just in the transition period to fatigue. Therefore, we still notice that there was an increment of spectral power in beta.

It seems obvious that driving in long period will also impair drivers' driving performance. Particularly in the driving period between first and ninth period, the RORIs and LSV index rise up significantly before it become constant near the end of task. Owing to all the drivers have no previous experience driving in simulator and they need times to adapt to the driving situation, thus they drove extra careful in the beginning of the task, especially in the first 10 minutes where the errors making is nearly to zero. After some times when they had familiarize the driving condition, they started to speed up and tend to make more errors which was seen by the increment of RORIs and LSVs after 20 minutes of driving (Figure 4). Nearly to 50 minutes till the end of task, drivers had achieved the maximum driving speed. Also, during that period, drivers are driving on monotonous highway which evidently can induce a more weary and drowsy state (Liu and $\mathrm{Wu}, 2009$ ). Thus, we observed a more constant errors making during that time.

\subsection{The effect of environmental factors on drivers' physiological data and driving performance}

Table 1 shows drivers' physiological change of all EEG indices increased significantly when changing from complex road environment (e.g. town area and trunk road) to a monotony highway, except (alpha theta)/beta band ratio. Indeed, changing in road environment from complex to monotonous caused drivers to feel weary. When switching from the complex to the monotonous road environment, drivers feel a greater sense of monotony, making them less alert (Liu and $\mathrm{Wu}, 2009$ ). This is evidenced with higher frequency in alpha and theta band when reaching the highway. However, drivers tend to show an increased of spectral power in beta which implied that drivers remained alert to a certain degree when driving in monotonous highway.

Similarly, we observed a higher driving errors occur on the highway with road curve and uphill downhill (Table 2), but the driving conditions have no consequences to this scenario. In truth, monotonous driving task provided little visual stimulation and make drivers gradually became drowsier and hence, ended with higher driving errors (Lui et al., 2009). Furthermore, the traffic density on highway was lighter compared to town or trunk road area, allowing the drivers tend to drive faster. The situation became worsen when drivers driving on uphill/ downhill and cornering road with the extensive higher speed. This explained why the driving performance was deteriorated on those area compared with others. Our study also supported by nearly 1 in five traffic crash resulted in driver casualty happened on state highway (Soufiane and Williamson, 2006) while 68 percent of traffic crash which described as lose control of vehicle occurred in either straight or around the road corner (Kingshott et al., 2004).

When considered the rain effect, we found no significant difference of all EEG spectral powers, either in daytime or night-time driving condition. However, we observed that drivers showed a low frequency of spectral power in alpha and theta band during raining, indicated that there was a high vigilance level presented among drivers, particularly when driving in night-time. An explanation of the result could pertained to the rain started to present when drivers reached the highway, thus they drove extra careful with the reduced in visibility, causing the theta band become lower compared with no rain driving condition. Besides, lighting was considered as one of the factor which can reduce driver's visibility, particularly when driving in a night-time condition. This has consequence drivers tend to drive in a more alert state when it is raining in a night-time environment.

This study also coincided with the findings of Zaharah and Law (2004), showing that accidents involved heavy vehicle and motorcycle most likely to occur in good weather but rainy weather gave highest relative risk to cause fatality. Hijar et al. (2000) agreed the fact, revealed that about 66.05 percent of traffic accident in Mexico happened in adverse weather. Owing to the visibility of road was reduced when the rain present, drivers started to reduce their vehicle speed or drove even slower than legal speed limit in the highway. Thus, they commit less in RORIs but high in LSV index.

\section{Conclusion}

Long haul driving on monotonous motorway is repetitive and boredom which occasionally can induce unwanted of driving fatigue and drowsiness among drivers. In this case, occupational drivers is one of the high risk group due to their job scope are normally need travelling. The situation may become worsen if the drivers are required to work in irregular working shift and suffer sleep deprivation. Indeed, we found that drivers become drowsier with the deteriorated in their driving performance during the simulated prolonged driving task. However, our 
studies shows no much effect of driving conditions towards the onset of drivers' fatigue or drowsiness pertaining to the time to carry out this experiment has been controlled in morning session. Looking from the changing of road environments from complex to monotony, drivers' vigilance level significantly deteriorated. Notwithstanding, we should take into consideration that the time on task effect may play an important role in interchange with road environment. The changing of road types from town, trunk road into monotonous highway was in sequent with times. Therefore, we do not deny that there was a possibility of time effect causing the variation of EEG indices and affect drivers' driving performance in certain degree. Also, adverse weather was one of the factors which contributed to driving errors. Surprisingly, our results showed different findings in contrast with previous studies. Perhaps, raining reduced drivers' visibility and therefore changed drivers' driving behavior to be more cautious. Thus, raining make drivers become more alert and perform better. Nevertheless, we should bear in mind that results obtained on driving simulator cannot fully reflect the real- driving situation as drivers knew that the consequences of their driving errors would not affect their safety. Furthermore, limitations due to insufficient number of subjects and the discrepancies in the results could be due to statistical limitation. Also, drivers may more motivate to maintain vigilance during actual driving than using simulator. Time course of fatigue may differ between individual as well. Hence from this study, we suggest further information of fatigue should be enhanced to prevent forthcoming fatigue-related accidents, exclusively involved occupational drivers.

\section{References}

Annual Report of Malaysian Institute of Road Safety Research. (2007). [Online] Available: http://www.miros.gov.my/

Campagne, A., T. Pebayle and A. Muzet. (2004). Correlation between driving errors and vigilance level: influence of the driver's age. Physiology \& Behavior, 80: 515- 524.

Dobbie, K. (2002). Fatigue related crashes: An analysis of fatigue-related crashes on Australian roads using an operational definition of fatigue. Commonwealth Department of Transport and Regional Services, Australian Transport Safety Bureau. [Online] Available: http://www.atsb.gov.au/

Hijar, M., C. Carrillo, M. Flores, R. Anaya and V. Lopez. (2000). Risk Factors in Highway Traffic Accidents: A Case Control Study. Accident Analysis and Prevention. 32: 703-709.

Kingshott, R. N., J. O. Cowan, D. R. Jones, E. M. Flannery, A. D. Smith, G. P. Herbison and D. R. Taylor. (2004). The role of sleep-disordered breathing, daytime sleepiness and impaired performance in motor vehicle crashes: a case control study. Sleep and Breathing. 8: 2.

Lal, S. K. L and A. Craig. (2001). A critical review of the psychophysiology of driver fatigue. Biological Psychology. 55: 173-194.

Liang, S. F., C. T. Lin, R. C. Wu, Y. C. Chen, T. Y. Hung and T. P. Jung. (2005). Monitoring driver's alertness based on the driving performance estimation and the EEG power spectrum analysis. Proceeding of the 2005 IEEE, Shanghai, China, Sept. 1-4, 2005. Engineering in Medicine and Biology 27th Annual Conference.

Liu, Y.C and T. J. Wu. (2009). Fatigued driver's driving behavior and cognitive task performance: Effects of road environments and road environment changes. Safety Science, 47: 1083-1089.

Lui, C. C., S. G. Hosking and M. G. Lenne. (2009). Predicting driver drowsiness using vehicle measures: Recent insights and future challenges. Journal of Safety Research, doi:10.1016/j.jsr.2009.04.005.

Meletis, C. D and J. E. Barker. (2004). Herbs and Nutrients for the Mind: A Guide to Natural Brain Enhancers. Greenwood Publishing Group, Westport. 118pp.

Muhammad, F. M. Y, Norlen, M., Ilhamah, O., Rohayu, S and S. V. Wong. (2008). Prevalence of fatigue among commercial bus drivers in Malaysia. Malaysian Institute of Road Safety Research. MRR 06/2008

Ng, W. K and Selva, P. (2003). OSH Profile in the transport sector in particular commuting hazard. [Online] Available: http://www.mtuc.org.my/osh_profile_transport.htm.

Norlen, M., Muhammad, F. M. Y, Ilhamah, 0., Rohayu, S and S. V. Wong. (2008). Fatigue among commercial bus drivers in Malaysia: Role of driving hours and single versus two-driver approach. Malaysian Institute of Road Safety Research. MRR 07/2008.

Otmani, S., T. Pebayle, J. Roge and A. Muzet. (2005). Effect of driving duration and partial sleep deprivation on subsequent alertness and performance of car drivers. Physiology and Behaviour, 84: 715-724.

Papadelis, C., Z. Chen, C. K. Papadeli, P. D. Bamidis, I. Chouvarda, E. Bekiaris and N. Maglaveras. (2007). 
Monitoring sleepiness with on-board electrophysiological recordings for preventing sleep-deprived traffic accidents. Clinical Neurophysiology, doi:10.1016/j.clinph.2007.04.031.

Philip, P., J. Taillard, E. Klein, P. Sagaspe, A. Charles, W. L. Davies, C. Guilleminault and B. Bioulac. (2003). Effect of fatigue on performance measured by a driving simulator in automobile drivers. Psychosomatic Research. 55: 197-200.

Philip, Pierre. (2005). Sleepiness of Occupational Drivers. Industrial Health, 43: 30-33.

Roge, J., T. Pebayle, E. Lambilliotte, F. Spitzenstetter, D. Giselbrecht and A. Muzet. (2004). Influence of age, speed and duration of monotonous driving task in traffic on the driver's useful visual field. Vision Research, 44: 2737-2744.

Schier, M. A. (2000). Changes in EEG alpha power during simulated driving: a demonstration. International Journal of Psychophysiology, 37: 155-162.

Soufiane, B and A. Williamson. (2006). Work-related traffic crashes: A record linkage study. Accident Analysis and Prevention, 38: 14-21.

Straus, S. E. (1994). Chronic fatigue syndrome. Informa Health Care. 54pp.

Tippayanate, N. (2006). The impact of sleep deprivation on driving performance. Khon Kaen Hospital Medical Journal, 30(3): 320-325.

Zaharah, S and T. H. Law. (2004). The establishing of heavy vehicle and motorcycle accident model. Malaysian Universities Transport Research Forum Conference: 1st-2nd December 2004; The Pan-Pacific Glenmarie, Shah Alam.

Table 1. Mean (SD) of EEG spectral powers by road conditions

\begin{tabular}{|c|c|c|c|c|c|c|c|c|}
\hline \multirow[t]{2}{*}{ EEG } & \multicolumn{6}{|c|}{ Road condition, mean (SD) } & \multirow{2}{*}{$\begin{array}{c}F \\
\text { (df) }\end{array}$} & \multirow{2}{*}{$\begin{array}{c}\text { P- } \\
\text { value }\end{array}$} \\
\hline & Town & $\begin{array}{l}\text { Trunk } \\
\text { road }\end{array}$ & $\begin{array}{l}\text { Highway } \\
\text { (after toll) }\end{array}$ & $\begin{array}{l}\text { Uphill \& } \\
\text { downhill }\end{array}$ & $\begin{array}{l}\text { Road } \\
\text { curve }\end{array}$ & Highway & & \\
\hline Alpha, $\alpha$ & $\begin{array}{c}0.04 \\
(0.11)\end{array}$ & $\begin{array}{c}0.02 \\
(0.12)\end{array}$ & $\begin{array}{c}0.05 \\
(0.13)\end{array}$ & $\begin{array}{c}0.06 \\
(0.13)\end{array}$ & $\begin{array}{c}0.06 \\
(0.15)\end{array}$ & $\begin{array}{c}0.08 \\
(0.14)\end{array}$ & $\begin{array}{c}4.803 \\
(2.74,65.78)\end{array}$ & $0.006^{* *}$ \\
\hline Beta, $\beta$ & $\begin{array}{c}0.14 \\
(0.13)\end{array}$ & $\begin{array}{c}0.14 \\
(0.15)\end{array}$ & $\begin{array}{c}0.18 \\
(0.16)\end{array}$ & $\begin{array}{c}0.18 \\
(0.15)\end{array}$ & $\begin{array}{c}0.20 \\
(0.15)\end{array}$ & $\begin{array}{c}0.23 \\
(0.14)\end{array}$ & $\begin{array}{c}10.866 \\
(3.15,75.56)\end{array}$ & $0.000^{* *}$ \\
\hline Theta, $\theta$ & $\begin{array}{c}0.21 \\
(0.10)\end{array}$ & $\begin{array}{c}0.18 \\
(0.10)\end{array}$ & $\begin{array}{c}0.20 \\
(0.10)\end{array}$ & $\begin{array}{c}0.22 \\
(0.10)\end{array}$ & $\begin{array}{c}0.23 \\
(0.11)\end{array}$ & $\begin{array}{c}0.25 \\
(0.13)\end{array}$ & $\begin{array}{c}5.352 \\
(3.56,85.40)\end{array}$ & $0.001 * *$ \\
\hline $\begin{array}{l}(\alpha \theta) / \beta \\
\text { ratio }\end{array}$ & $\begin{array}{c}1.20 \\
(0.22)\end{array}$ & $\begin{array}{c}1.07 \\
(0.23)\end{array}$ & $\begin{array}{l}1.10 \\
(0.19)\end{array}$ & $\begin{array}{c}1.16 \\
(0.24)\end{array}$ & $\begin{array}{c}1.11 \\
(0.17)\end{array}$ & $\begin{array}{l}1.12 \\
(0.19)\end{array}$ & $\begin{array}{c}1.881 \\
(3.49,69.89)\end{array}$ & 0.132 \\
\hline
\end{tabular}

$* * \mathrm{p}<0.01$; df were corrected using epsilon Huynh-Feldt estimates of sphericity.

Table 2. Mean (SD) of driving errors by road conditions

\begin{tabular}{|c|c|c|c|c|c|c|c|c|}
\hline \multirow[t]{2}{*}{ Variable } & \multicolumn{6}{|c|}{ Road condition, mean (S.D) } & \multirow{2}{*}{$\begin{array}{c}\mathrm{F} \\
\text { (df) }\end{array}$} & \multirow[t]{2}{*}{ P-value } \\
\hline & Town & $\begin{array}{l}\text { Trunk } \\
\text { road }\end{array}$ & $\begin{array}{l}\text { Highway } \\
\text { (after toll) }\end{array}$ & $\begin{array}{l}\text { Uphill \& } \\
\text { downhill }\end{array}$ & $\begin{array}{l}\text { Road } \\
\text { curve }\end{array}$ & Highway & & \\
\hline RORI & $\begin{array}{c}7.09 \\
(3.57)\end{array}$ & $\begin{array}{l}10.40 \\
(3.39)\end{array}$ & $\begin{array}{l}17.08 \\
(8.95)\end{array}$ & $\begin{array}{c}52.50 \\
(15.40)\end{array}$ & $\begin{array}{c}44.29 \\
(13.45)\end{array}$ & $\begin{array}{c}54.22 \\
(12.30)\end{array}$ & $\begin{array}{c}180.31 \\
(2.11,50.63)\end{array}$ & $0.000^{* *}$ \\
\hline LSV & $\begin{array}{c}0.06 \\
(0.22)\end{array}$ & $\begin{array}{c}59.75 \\
(32.29)\end{array}$ & $\begin{array}{l}137.61 \\
(38.80)\end{array}$ & $\begin{array}{l}171.87 \\
(67.59)\end{array}$ & $\begin{array}{l}168.97 \\
(49.44)\end{array}$ & $\begin{array}{l}192.26 \\
(53.18)\end{array}$ & $\begin{array}{c}122.09 \\
(2.57,61.78)\end{array}$ & $0.000 * *$ \\
\hline
\end{tabular}

$* * \mathrm{p}<0.01$; df were corrected using epsilon Huynh-Feldt estimates of sphericity. 
Table 3. Mean of EEG spectral powers by rain event between two daytime and night-time driving condition

\begin{tabular}{|c|c|c|c|c|c|c|c|}
\hline \multirow[t]{2}{*}{ EEG } & \multirow[t]{2}{*}{ Event } & \multirow{2}{*}{$\begin{array}{l}\text { Driving } \\
\text { condition }\end{array}$} & \multirow[t]{2}{*}{ Mean } & \multicolumn{2}{|c|}{$95 \% \mathrm{CI}$ of difference } & \multirow{2}{*}{$\begin{array}{l}\text { F stat } \\
\text { (df) }\end{array}$} & \multirow[t]{2}{*}{ P-value } \\
\hline & & & & Lower & Upper & & \\
\hline \multirow[t]{4}{*}{ Alpha, $\alpha$} & \multirow[t]{2}{*}{ Rain } & Daytime & 0.06 & -0.01 & 0.14 & \multirow{4}{*}{$\begin{array}{l}0.192 \\
(1,46)\end{array}$} & \multirow[t]{4}{*}{0.663} \\
\hline & & Night-time & 0.04 & -0.04 & 0.11 & & \\
\hline & \multirow[t]{2}{*}{ No rain } & Daytime & 0.10 & 0.03 & 0.17 & & \\
\hline & & Night-time & 0.04 & -0.04 & 0.12 & & \\
\hline \multirow[t]{4}{*}{ Beta, $\beta$} & \multirow[t]{2}{*}{ Rain } & Daytime & 0.16 & 0.08 & 0.24 & \multirow{4}{*}{$\begin{array}{l}0.268 \\
(1,46)\end{array}$} & \multirow[t]{4}{*}{0.607} \\
\hline & & Night-time & 0.20 & 0.12 & 0.29 & & \\
\hline & \multirow[t]{2}{*}{ No rain } & Daytime & 0.20 & 0.12 & 0.29 & & \\
\hline & & Night-time & 0.20 & 0.12 & 0.29 & & \\
\hline \multirow[t]{4}{*}{ Theta, $\theta$} & \multirow[t]{2}{*}{ Rain } & Daytime & 0.22 & 0.16 & 0.27 & \multirow{4}{*}{$\begin{array}{l}0.514 \\
(1,46)\end{array}$} & \multirow[t]{4}{*}{0.477} \\
\hline & & Night-time & 0.19 & 0.13 & 0.25 & & \\
\hline & \multirow[t]{2}{*}{ No rain } & Daytime & 0.27 & 0.21 & 0.32 & & \\
\hline & & Night-time & 0.20 & 0.14 & 0.26 & & \\
\hline \multirow{4}{*}{$\begin{array}{l}(\alpha \theta) / \beta \\
\text { ratio }\end{array}$} & \multirow[t]{2}{*}{ Rain } & Daytime & 1.30 & 1.16 & 1.44 & \multirow{4}{*}{$\begin{array}{l}1.239 \\
(1,41)\end{array}$} & \multirow[t]{4}{*}{0.272} \\
\hline & & Night-time & 1.10 & 0.96 & 1.24 & & \\
\hline & \multirow[t]{2}{*}{ No rain } & Daytime & 1.17 & 1.00 & 1.33 & & \\
\hline & & Night-time & 1.13 & 0.99 & 1.27 & & \\
\hline
\end{tabular}

$P$ value is not significant at $\mathrm{p}>0.05$.

Table 4. Mean of driving errors by rain event between daytime and night-time driving condition

\begin{tabular}{|c|c|c|c|c|c|c|c|}
\hline \multirow[t]{2}{*}{ Variable } & \multirow[t]{2}{*}{ Event } & \multirow{2}{*}{$\begin{array}{l}\text { Driving } \\
\text { condition }\end{array}$} & \multirow[t]{2}{*}{ Mean } & \multicolumn{2}{|c|}{$95 \% \mathrm{CI}$ of difference } & \multirow{2}{*}{$\begin{array}{c}\text { F stat } \\
\text { (df) }\end{array}$} & \multirow[t]{2}{*}{ P-value } \\
\hline & & & & Lower & Upper & & \\
\hline \multirow[t]{4}{*}{ RORI } & \multirow[t]{2}{*}{ Rain } & Daytime & 28.59 & 23.56 & 33.63 & \multirow{4}{*}{$\begin{array}{l}2.207 \\
(1,42)\end{array}$} & \multirow[t]{4}{*}{0.145} \\
\hline & & Night-time & 22.21 & 16.97 & 27.45 & & \\
\hline & \multirow[t]{2}{*}{ No rain } & Daytime & 42.66 & 37.18 & 48.13 & & \\
\hline & & Night-time & 44.20 & 38.45 & 49.94 & & \\
\hline \multirow[t]{4}{*}{ LSV } & \multirow[t]{2}{*}{ Rain } & Daytime & 151.02 & 129.10 & 172.93 & \multirow{4}{*}{$\begin{array}{l}0.004 \\
(1,46)\end{array}$} & \multirow[t]{4}{*}{0.950} \\
\hline & & Night-time & 147.72 & 124.92 & 170.53 & & \\
\hline & \multirow[t]{2}{*}{ No rain } & Daytime & 132.70 & 110.79 & 154.62 & & \\
\hline & & Night-time & 128.01 & 105.20 & 150.82 & & \\
\hline
\end{tabular}

$\mathrm{P}$ value is not significant at $\mathrm{p}>0.05$. 


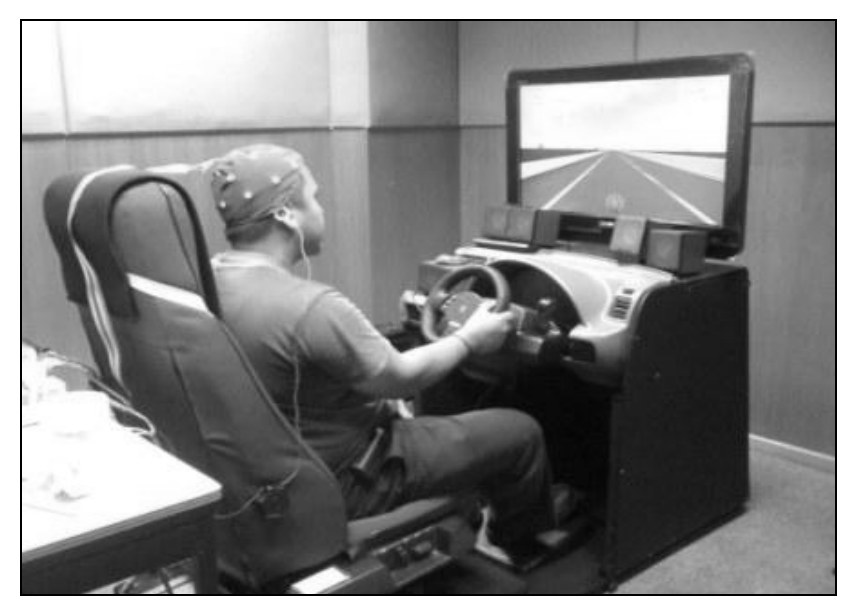

Figure 1. Driving simulator system

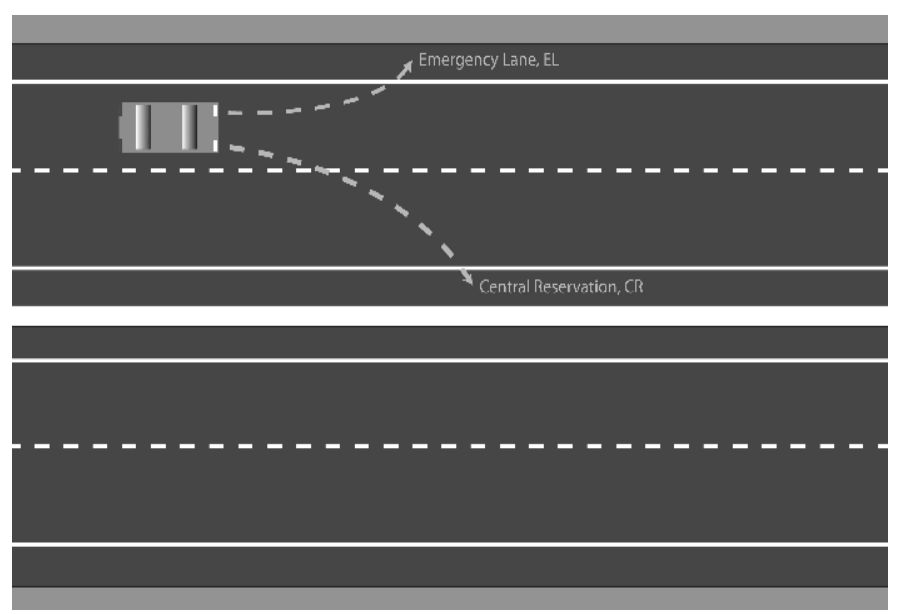

Figure 2. RORIs 


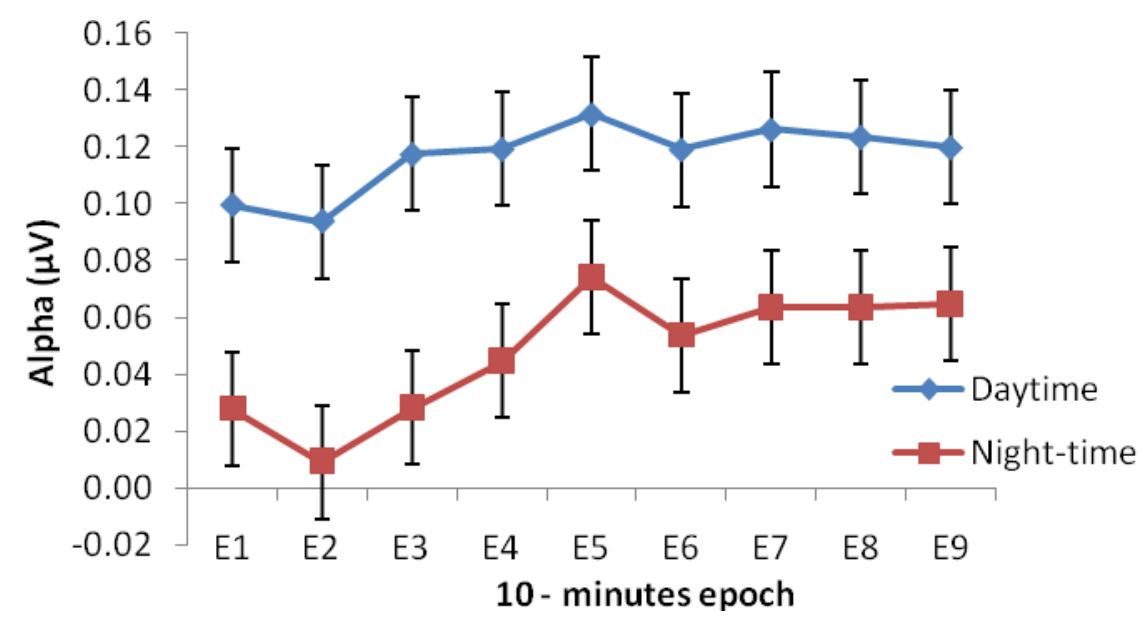

a) Spectra power in alpha band, $8-12 \mathrm{~Hz}$

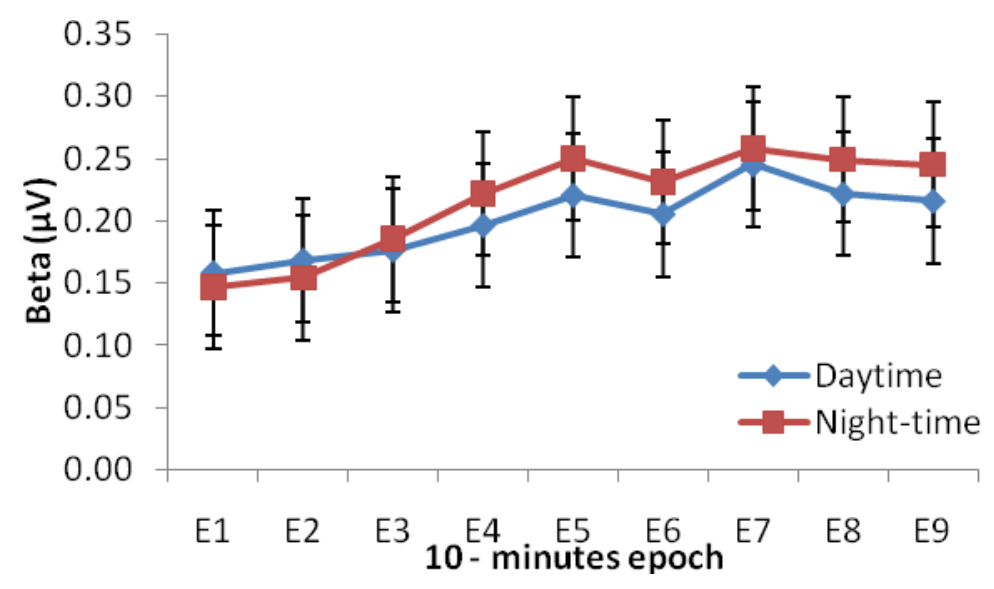

b) Spectra power in beta band, $12-25 \mathrm{~Hz}$

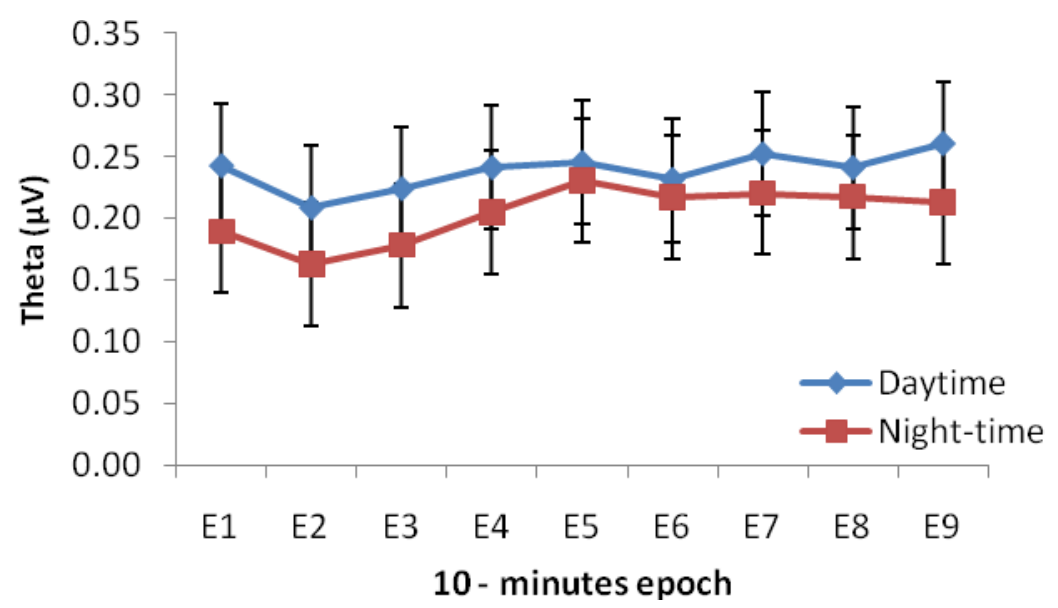

c) Spectra power in theta band, $4-8 \mathrm{~Hz}$

Figure 3. The physiological change of EEG spectra power by driving time (epoch 1-10) 


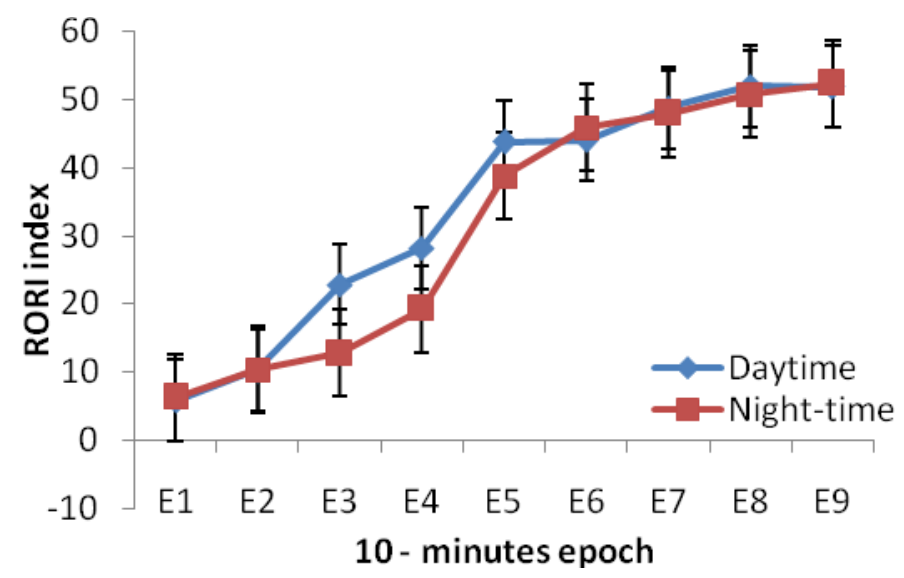

a) Running-off-road index (means \pm standard errors)

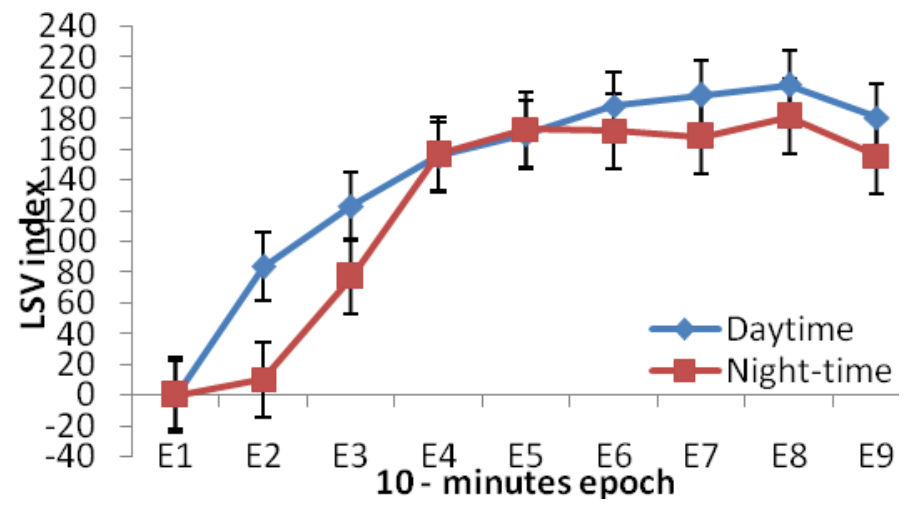

b) Large speed variation (means $\underline{ \pm}$ standard errors)

Figure 4 . The variations of driving performance index by driving time (period 1-10) 